\title{
Insights towards Native and Non-native ELT Educators
}

\author{
Nuria Villalobos Ulate \\ Universidad Nacional, Costa Rica
}

\section{Introduction}

Throughout the years, the terms Native and Non-native have been used to refer to speakers of a language. As it is well-known, not all native speakers teaching a language have the necessary credentials to do so. Nevertheless, "it is often taken for granted that the only rightful speakers of a language are its native speakers” (Cook 1999: para 1).

Sometimes, qualified non-native English speaking teachers are not considered good enough by administrators in order to get teaching jobs. In some cases, students do not realize how much they can learn from a non-native speaking teacher because they simply believe a native speaker is the best. According to Moussu and Llurda (2008: 316), "the myth of the native speaker as the ideal teacher has been deconstructed through showing the lack of substantial evidence behind such a concept”. Studies have shown that both native and non-native speakers have certain characteristics that help them become good language professionals. As a result, a good language teacher is neither native nor non-native, but that one that is professionally and personally prepared to perform the demanding task of educating others.

The purpose of this paper is, by no means, to conclude which language teacher is better: a native or non-native English speaker. Instead, it strives to create awareness regarding this issue and recognize the strengths of native and non-native educators so they can all benefit. Finally, with the purpose of finding out the teachers' perceptions on this subject, an online survey was carried out to 113 teachers in ESL or EFL contexts. 


\section{Native vs. non-native English speakers}

The British Council estimates that English is spoken as a second language by about 375 million speakers and as a foreign language by about 750 million speakers; subsequently, the majority of English teachers are non-native speakers (Cheung and Braine 2007: 2). Another important fact the British Council states is that the speakers of English as a second language probably outnumber those who speak it as a first language. “...the English language is no longer the privilege of native speakers [...] Nevertheless, people who speak English as their native language continue to have a distinct advantage over those for whom it is a foreign tongue” (Medgyes 2001: 429).

When we say "English as a second (or even third or fourth) language", we must do so with reference to something, and that standard of measure must, given the nature of the label, be English as someone's first language. This automatically creates attitudinal problems, for it is almost unavoidable that anyone would take "second" as less worthy, in the sense, for example, that coming in second in a race is not as good as coming in first. (Kachru and Nelson 1996: 79 in Mahboob 2005: 18)

Mahboob (2005) explains that this statement reflects awareness that terms like first language and second language are not neutral but attitudinal loaded (as is the term native speaker). In his article Going beyond the Native Speaker in Language Teaching, Cook (1999) states that abandoning the native speaker totally may be unrealistic since the stereotype is so entrenched in teachers' and students' minds, and so language teaching should be more aware of the student as a potential and actual L2 user and less concerned with the monolingual native speaker.

The term non-native English speaker is frequently considered negative by language professionals, undoubtedly because of comparing it to native English speaker, which is usually thought of as positive. Matsuda (2001) argues that,

It cannot be the combination of the prefix non- with a human referent that bothers them, especially if you consider examples such as nontraditional students, nonsmokers, noncriminals, and nonfascists. It is not really the non- part that people find unfortunate. For nonnative to be a pejorative term, its counterpart would have to be positive. Nonnative is unfortunate because native is supposed to

Bellaterra Journal of Teaching \& Learning Language \& Literature. 4.1 (January 2011): 56-79. ISSN 2013-6196. 
be fortunate. Nonnative is marked, whereas native is unmarked. Non-native is marginal, and native is dominant. Nonnative is negative, and native is positive (para 3 and 4).

Issues related to non-native English teachers have been studied only recently, which is probably why this belief still exists. It is clear then that "the assumption that native is somehow more positive than nonnative needs to be challenged” (Matsuda 2001: para 5).

Péter Medgyes was one of the first researchers to explore the notion of non-native language professionals. Because every teacher is either a native English speaker (NES) or a non-native English speaker (NNES), Medgyes (2001) proposes four hypotheses about them:

-They differ in terms of their language proficiency.

-They differ in terms of their teaching behavior.

-The discrepancy in language proficiency accounts for most of the difference found in their teaching behavior.

-They can be equally good teachers on their own terms (p. 434).

\section{The non-native English-speaking teacher}

According to Mydans (2007), the largest English-speaking nation in the world, the United States, has only about 20 percent of the world's English speakers. In Asia alone, an estimated 350 million people speak English, about the same as the combined Englishspeaking populations of Britain, the United States and Canada.

A non-NEST may be defined, as Medgyes (2001) points out, as a teacher:

-for whom English is a second or foreign language;

-who works in an EFL environment;

-whose students are monolingual groups of learners;

-who speaks the same native language as his or her students (p. 433).

"The term nonnative-English-speaking teachers (NNESTs) has created a division among professionals in the ELT profession” (Maum 2002: 1). Maum (2002) also argues that people who support the term believe it is necessary to distinguish between NES and NNES teachers because their differences are, in fact, their strengths and should be recognized. The ones opposing think that differentiating among teachers based on their 
status as native or nonnative speakers perpetuates the dominance of the native speaker, which contributes to discrimination in hiring practices.

As already mentioned in this paper, non-native teachers of English are sometimes discriminated against merely because of their non-native status. In the article When the Teacher Is a Non-native Speaker, Medgyes (2001) explains that teaching applications from even highly qualified and experienced non-NESTs often get turned down in favor of NESTs with no such credentials. This is illustrated with a letter of rejection sent to a nonNEST applicant by the principal of a language school in London saying: "I am afraid we have to insist that all our teachers are native speakers of English. Our students do not travel halfway round the world only to be taught by a non-native speaker (however good that person’s English may be)” (Illés 1991, p. 87 in Medgyes 2001: 432).

\section{The native speaker fallacy}

The native speaker fallacy refers to the unfair treatment of qualified NNES teachers.

The term was coined as a reaction to the tenet created at the 1961 Commonwealth Conference on the Teaching of English as a Second Language in Makarere, Uganda, which stated that the ideal teacher of English is a native speaker (Maum 2002: 1).

Nevertheless, having English as one's mother tongue does not automatically qualify anyone to teach the language, and NNESTs can be trained to obtain the necessary knowledge native speakers possess. Moreover, non-native English teachers are sometimes excluded from ESL classrooms even though they could highly contribute their rich multicultural and multilingual experience. Ironically, ESL students are often valued for the diversity and multiculturalism they bring into language classes.

Due to the native speaker fallacy, non-native English speaking teachers face a number of challenges in their struggle for equal treatment in the ELT profession. Maum (2002) refers to two of them: accent and credibility in the workplace. Her article describes how the issue of accent has often been the cause of employment discrimination practices in ESL programs in the United States and other countries: "teachers with nonnative accents were perceived as less qualified and less effective and were compared 
unfavorably with their native-English-speaking colleagues” (Lippi-Green 1997 in Maum 2002: 1). This form of linguistic discrimination also occurs when English teachers from countries such as India and Singapore are considered less credible and less competent because of not belonging to a country from the Inner Circle (see Kachru 2005, for more information about the Three Concentric Circles).

\section{The issue of accent}

In April 2010, a new policy from the Arizona Department of Education seeking to reassign teachers who spoke with heavy accents created controversy in the United States. In the article Arizona Cracks Down on Teachers with Heavy Accents, Edwards (2010) explained that "State auditors had reported to the district that some teachers pronounce words such as violet as biolet, think as tink and swallow the ending sounds of words, as they sometimes do in Spanish" (para 4). State education officials denied any discrimination against teachers, saying they were acting in students' best interest. According to University of Arizona professor Roseann Gonzalez, "studies have shown that non-native teachers actually make better educators and that the ability to pronounce the language is not the most important aspect to learning” (Edwards 2010: para 9).

In another article, Prabhu (2010) says that Teachers of English to Speakers of Other Languages (TESOL) and its Arizona affiliate issued a joint statement expressing the organizations' disappointment with the department's recommendation. The statement read:

For decades the field of English language teaching has suffered from the myth that one only needs to be a native English speaker in order to teach the English language. The myth further implicates that native English speakers make better English as a second language or English as a foreign language teachers than nonnative speakers of English, because native English speakers are perceived to speak 'unaccented' English and understand and use idiomatic expressions fluently (Prabhu 2010: 1).

"But even native speakers have varied accents all over the U.S. The way it's been reported, [the definition of 'accent'] is very vague” (Pasquale 2010 in Prabhu 2010: 1). In

Bellaterra Journal of Teaching \& Learning Language \& Literature. 4.1 (January 2011): 56-79. ISSN 2013-6196. 
fact, what is an accent? An accent is “no more than one's way of speaking, the way one sounds when speaking, the way one uses sound features such as stress, rhythm and intonation” (Kumaravadivelu 2008, p. E4 in Braine 2010: 18). Therefore, Braine claims that everyone, both native speakers and non-native speakers, speaks with an accent. In the case of NSs of English, accent may be determined by the geographical area or social class to which speakers belong. In the case of NNSs, the accent is related to one's mother tongue. What is critical, then, is not accent but intelligibility -that is, "being understood by an individual or a group of individuals at a given time in a given communicative context” (Kumaravadivelu, 2008, p. E4 in Braine 2010: 19).

\section{Credibility as professionals}

The multifaceted nature of discriminatory hiring practices in the ELT profession reinforces the existing asymmetry in the perceived credibility of NESTs and NNESTs. "In this scenario, native speakers are believed to be equipped with a genetically endowed capacity to teach the language, whereas non-native speakers are perceived as deficient imitators of the language they are trying to learn” (Selvi 2010: 174). The research results of his study documented that native speakerism was more important than relevant education background and sufficient teaching experience. Selvi (2010) continues to question:

What might be the rationale behind assuming that a student who graduates as a marine biologist, petroleum engineer, or software developer can successfully meet the expectations of the students in a classroom in rural Thailand, metropolitan Tokyo, or suburban Beijing, only as a result of a few weeks of training, provided that he or she is a native speaker of English? (p. 175)

According to Maum (2002), some NNESTs have reported that many of their students resented being taught by a nonnative speaker until they were able to prove that they could be as effective as a native-English-speaking teacher. In reality, speakers of more than one language have both a sophisticated awareness of language and the ability to relate to students’ needs (Canagarajah, 1996; Phillipson, 1992 in Maum 2002: 1).

Bellaterra Journal of Teaching \& Learning Language \& Literature. 4.1 (January 2011): 56-79. ISSN 2013-6196. 
A study of ESL students' perceptions of their NNESTs showed that the student participants had positive attitudes toward their NNESTs, who at the same time scored higher on affective factors (e.g., more patient, understanding, and caring) than NESTs who had never learned another language (Park and Shin 2010: 101, 102). Likewise, in another study of the perceptions of students enrolled in an intensive English program:

Mahboob (2004) found that students perceived NESTs to be best at teaching oral skills, vocabulary, and culture and NNESTs to be more effective in teaching literacy skills and grammar. Students in his study recognized the unique attributes of NESTs and NNESTs and sought to benefit from interacting with both groups (Park and Shin 2010: 102).

\section{Native and non-native English-speaking teachers' attributes}

After a detailed description of how native and non-native English speaking teachers might be considered, it is impossible to decide which one is better. Indeed, both possess certain attributes that could facilitate the teaching process. Native speakers possess the following characteristics:

-Subconscious knowledge of rules.

-Intuitive grasp of meanings.

-Ability to communicate within social settings.

-Range of language skills.

-Creativity of language use.

-Identification with a language community.

-Ability to produce fluent discourse.

-Knowledge of differences between their own speech and that of the 'standard' form of the language.

-Ability 'to interpret and translate into the L1 of which she or he is a native speaker'. (Stern 1983; Johnson \& Johnson 1998; Davies 1996 in Cook 1999: para 3)

Medgyes (2001) characterizes NNESTs as:

-Good role models.

-Effective providers of learning strategies.

-Suppliers of information about the English language.

-Better anticipators of language learning difficulties.

Bellaterra Journal of Teaching \& Learning Language \& Literature. 4.1 (January 2011): 56-79. ISSN 2013-6196. 
-Sensitive to language learners' needs.

-Facilitators of language learning as a result of a shared mother tongue (p. 436).

As mentioned by Moussu and Llurda (2008), in 1992, Medgyes wrote the first article comparing native and nonnative English-speaking teachers, in which it was stated that:

-the ideal NS teacher is the one who has achieved a high degree of proficiency in the learners' mother tongue;

-the ideal NNS teacher is the one who 'has achieved near-native proficiency' in English (Medgyes 1992: 348f: 322 in Moussu and Llurda 2008: 322).

"Canagarajah (1999) added that NSs will be better teachers in EFL contexts, because of their unique cultural knowledge, whereas NNSs will be better teachers in ESL contexts, because of their multicultural experience” (Moussu and Llurda 2008: 322). Interestingly, this claim is not supported at all by TESOL practicum supervisors, who seem to believe that NNS teachers would be better teachers in their own countries (Llurda 2005b ibis). Medgyes (2001) claims that in an ideal school there should be a good balance of NESTs and non-NESTs, who complement each other in their strengths and weaknesses (p.441).

In fact, in the article When the Teacher is a Non-native Speaker, Medgyes (2001) examines the differences in teaching behavior between native and non-native teachers of English. The following table is based on a survey carried out to 325 native and non-native speaking teachers (p. 435).

Table 1: Perceived differences in teaching behavior between NESTs and Non-NESTs

\begin{tabular}{lll}
\hline \multicolumn{1}{c}{ NESTs } & Own use of English & \\
\hline Speak better English & & Speak poorer English \\
\hline Use real language & & Use “bookish” language \\
\hline Use English more confidently & Use English less confidently \\
\hline & General attitude & \\
\hline Adopt a more flexible approach & Adopt a more guided approach \\
\hline Are more innovative & Are more cautious \\
\hline Are less empathetic & Are more empathetic \\
\hline Attend to perceived needs & Attend to real needs \\
\hline Have far-fetched expectations & Have realistic expectations \\
\hline Are more casual & Are stricter \\
\hline Are less committed & Are more committed \\
\hline & & \\
\hline Are less insightful & Attitude to teaching the & \\
\hline Focus on: & language & Are more insightful \\
\hline
\end{tabular}




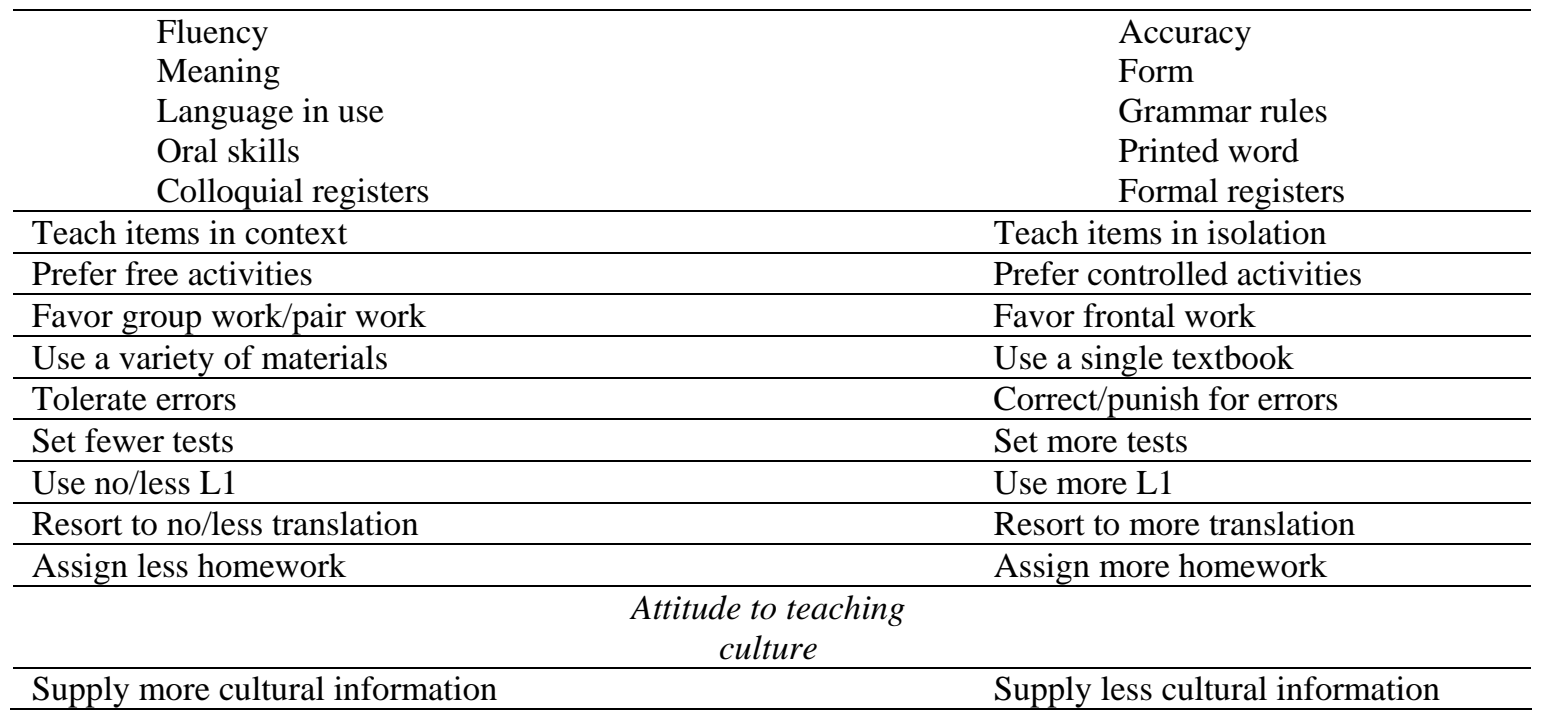

\section{The study}

In order to find out what English language professionals think of native and non-native English speaking teachers, an online questionnaire designed by the researcher was conducted during the month of October 2010. The survey for native speakers was made up of 17 questions, while the one for non-native speakers had 19 questions. It was completed by 113 teachers, 65 NESTs and 48 NNESTs, working in ESL or EFL settings. All solicitants, except for 1 , fully responded to the survey.

The majority of them speak at least two languages (NESTs: 49\% and NNESTs: $52 \%)$, which is probably why they believe that speaking a second language helps teachers better understand students' learning process (92\% in both). Most English teachers mentioned in the survey that they have had the experience of working in both ESL and EFL contexts, in spite of their native status. 92\% of the NESTs currently teach or have taught in an ESL environment and 61\% in an EFL environment. On the other hand, 96\% of the NNESTs teach or have taught in an EFL context and 74\% in an ESL context.

When asked what constitutes an ideal teacher, only 1 out of the 133 participants made reference to the native status: “A NNEST has higher English language proficiency which is closed to a native English speaker.” The purpose of the question was precisely to 
find out if teachers believe that the notion of an ideal teacher has to do with the fact of being native or non-native. Most answers can be summarized as: "One who has the knowledge, the skills and the personality to be a teacher”. Some of the characteristics mentioned are: creative, patient, motivating, encouraging, understanding and able to meet the students' needs.

In addition, 67\% of NESTs and 62\% of NNESTs showed preference for teaching certain language skills. In the case of native speakers, they favor teaching grammar, writing, reading, listening and culture; on the other hand, non-native speakers like to teach pronunciation and culture better. This seems contradictory to the wide belief that because non-native speakers' deficiencies are thought to be in the oral part, they prefer to teach grammar and writing. In some cases, they are even asked to teach only the grammar and writing courses because of the same reason. Medgyes (2001) pointed out that,

[...] non-NESTs are usually preoccupied with the nuts and bolts of grammar, the printed word...many lack fluency... have poor listening and speaking skills...It is only logical to assume that non-NESTs place an emphasis on those aspects of the language that they have a better grasp of (p. 434).

Interestingly, most participants believe this preference for teaching those skills has nothing to do with the fact that they are either native or non-native speakers of English (38\% of NESTs and $44 \%$ of NNESTs).

A few teachers think it has relation though: "I focus my ESL/EFL/ESP classes on overall English Communication, which first focuses on gaining confidence of speaking when non-native speakers have a lot of good grammar background yet cannot speak well”, "Definitely my dislike for teaching listening/speaking has to do with my nonnative status”, “As a non-native speaker I was taught both English language and how to teach it with a strong emphasis on grammar, listening and reading. These are areas I am strong at and can teach better”. However, the big majority expressed that this preference is based on their own interests and learning styles.

Bellaterra Journal of Teaching \& Learning Language \& Literature. 4.1 (January 2011): 56-79. ISSN 2013-6196. 


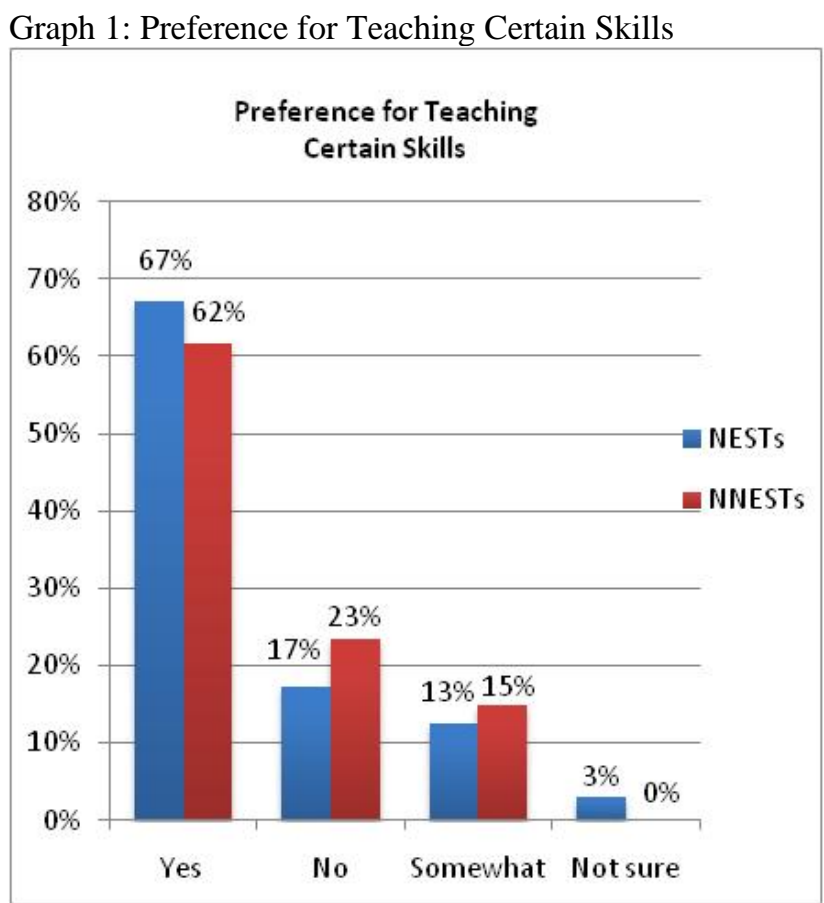

As to how necessary it is for an English teacher to be a native English speaker, 55\% of both NESTs and NNESTs answered not at all. Similarly, when asked if it was better to be taught by a non-native speaker, NESTs responded no (50\%) and not sure (31\%). On the contrary, NNESTs were asked if it was better to be taught by a native speaker, to which $57 \%$ replied no and 23\% somewhat.

All in all, participants expressed how both bring valuable things to teaching since NESTs and NNESTs have advantages and disadvantages. "It really depends on the individual not the nationality. Good qualified NN teachers can teach just as well as good qualified N teachers”, “Being a NS doesn't mean that it is an indication of a better teacher, some say NSs are good models of pronunciation, but with the Internet anybody can have access to authentic English language, especially for teaching materials for NNTs' use”. 
Graph 2: NESTs' Opinion on Being Better Taught by NNESTs

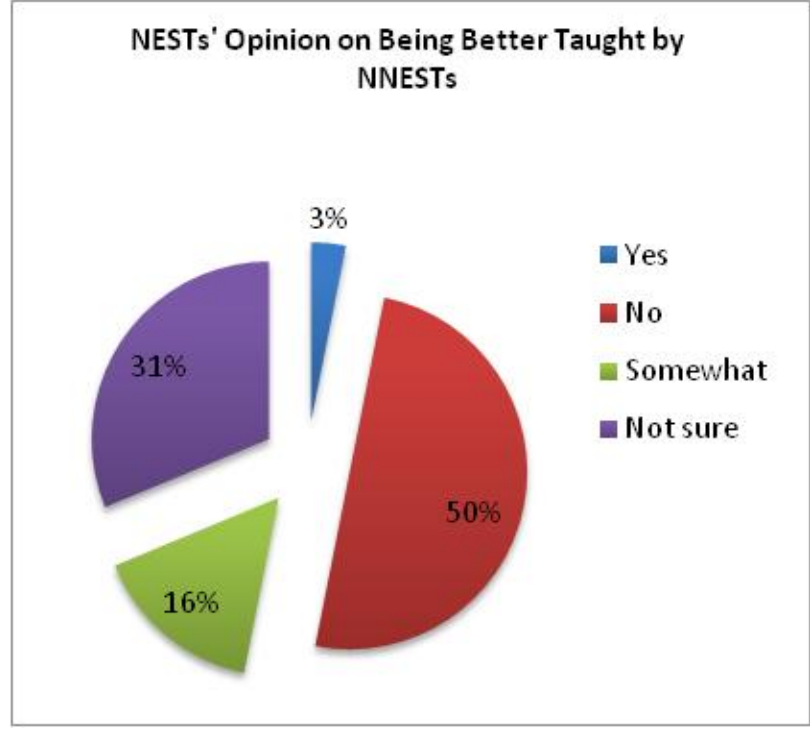

Graph 3: NNESTs’ Opinion on Being Better Taught by NESTs

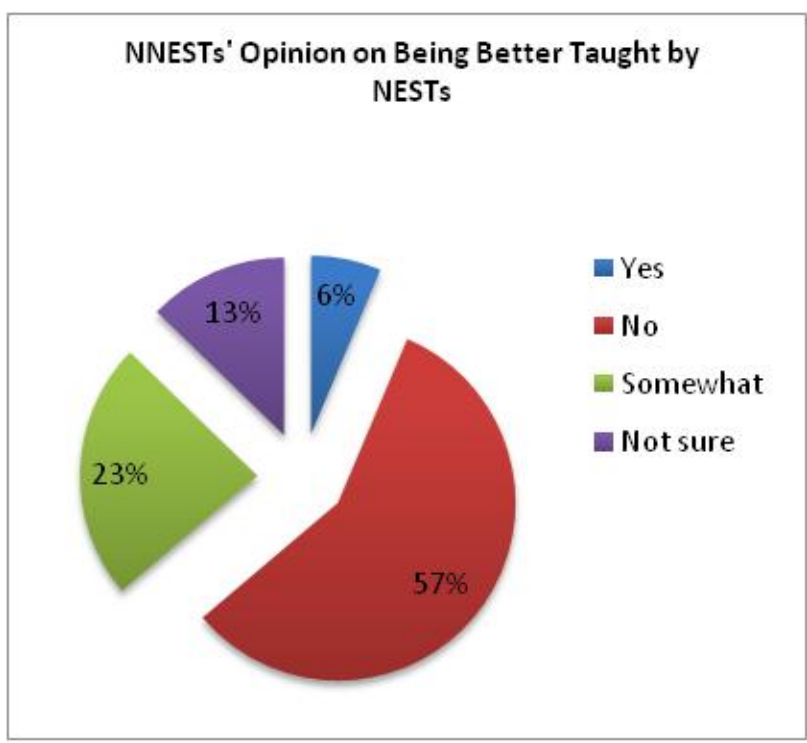

One item in the survey inquired whether the participants thought students consider an English teacher's native language important or not. While the highest percentage of NESTs chose somewhat (45\%), NNESTs selected yes and somewhat with the same percentage (32\%).

Bellaterra Journal of Teaching \& Learning Language \& Literature. 4.1 (January 2011): 56-79. ISSN 2013-6196. 
Graph 4: Importance of Teacher's L1 for Students

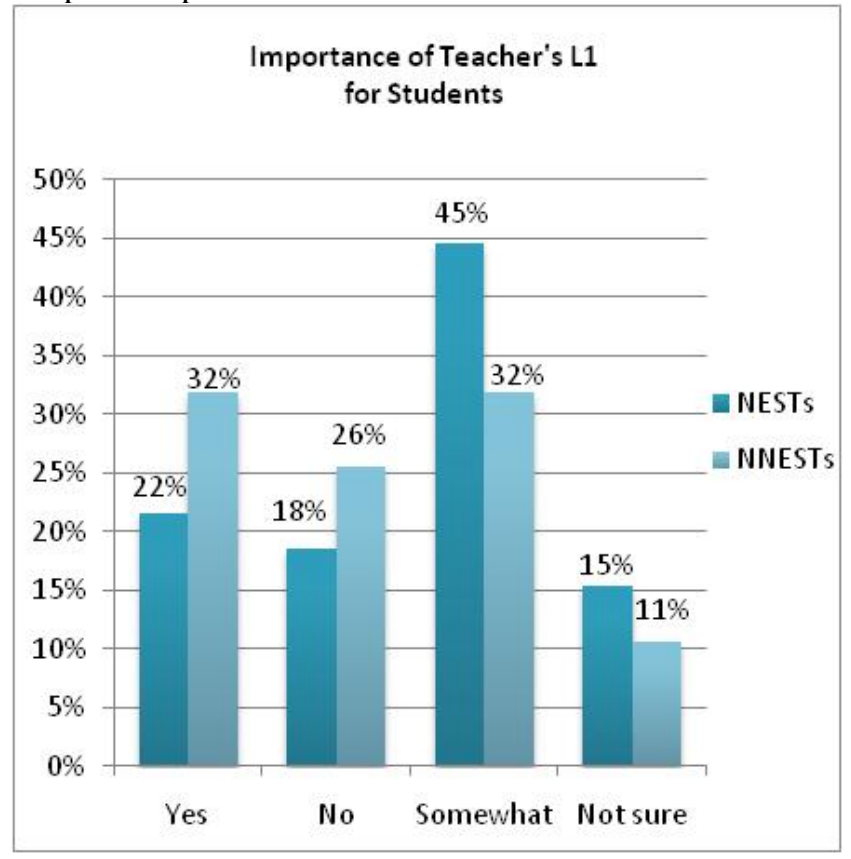

Likewise, teachers were also asked what they believed students generally prefer to have as an English teacher. Most participants indicated a native speaker (NESTs: 54\% and NNESTs: 41\%), and it depends on the skill taught (NESTs: 32\% and NNESTs: 35\%). Many respondents, especially non-native speakers, referred to the native speaker fallacy: "Students often think that they might be taught 'incorrect' English by a non-native speaker", "Well, the general perception that being a native speaker, that person would automatically be a better teacher", "It is a stereotype and myth that native speaker will provide the best input and teaching in class”. 
Graph 5: Students' Preference for an English Teacher

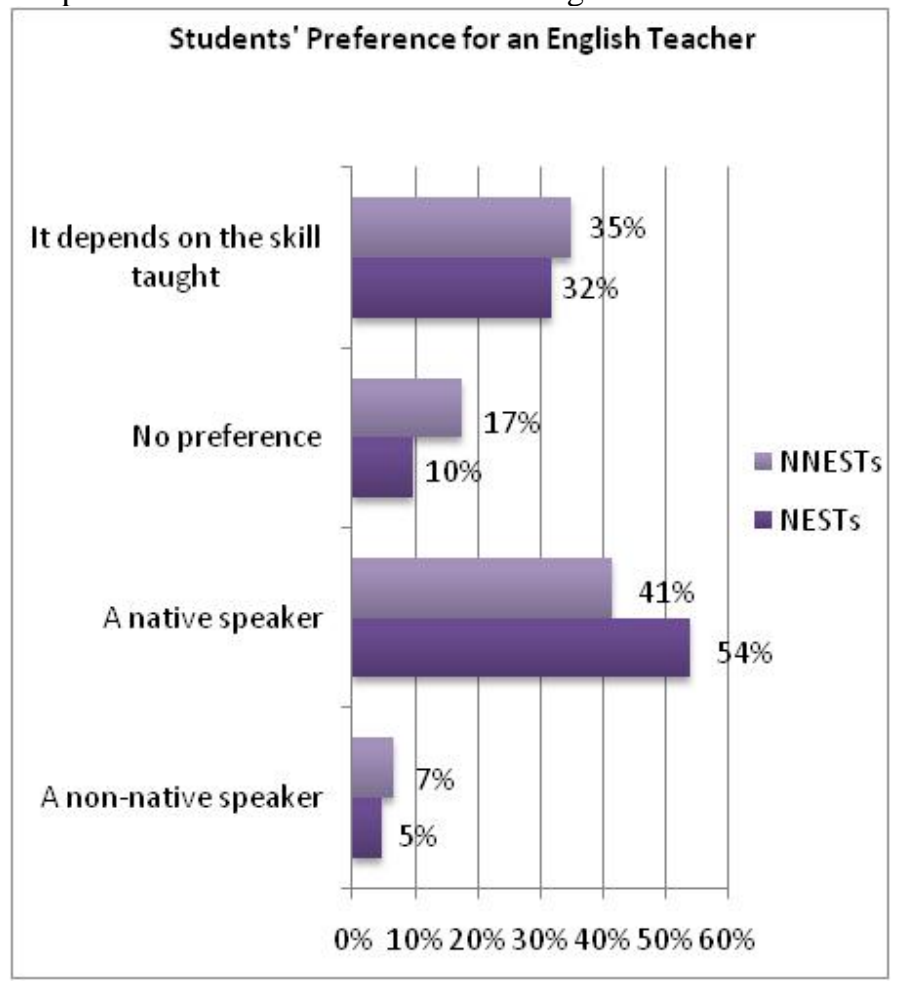

In terms of discrimination, $48 \%$ of NESTs mentioned not having been discriminated against because of their native status while $42 \%$ of them answered affirmatively. Some reasons are related to hiring practices, preference to the local language ethnic group and being forced to teach certain skills such as speaking over grammar. Other examples are: "Being treated like very poorly because you are just there to make the school look good", “I’ve had people assume that I didn’t speak Spanish and say very rude things in front of me, about me”, “When I was in Italy I was discriminated against because I couldn’t speak as well and had an accent”.

In the case of NNESTs, 51\% have been discriminated against while $43 \%$ have not. The participants gave examples associated with hiring practices, accent, differences in payment, being asked to prove English proficiency even when having teaching credentials and not being taken as seriously as native speakers. Others said: "Students rush to judge us just by our looks before they even know about our teaching styles and 
experiences", "Feeling like you do not belong”, "Students insist that I should not teach English in an ESL environment, because my first language is not English”.

Graph 6: Being Discriminated Against Due to Native Status

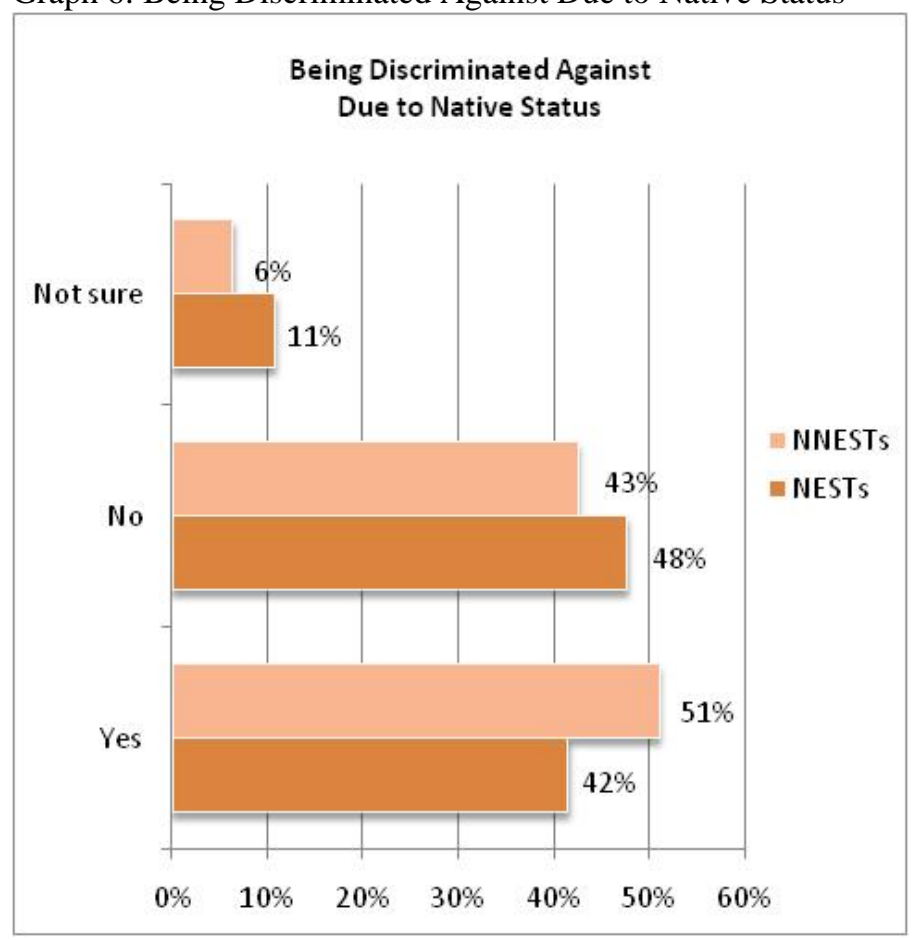

Moreover, for $57 \%$ of the non-native respondents, having an accent does not bother them; indeed, 45\% of them believe that having an accent could not negatively affect a language educator's teaching. In contrast, native speakers consider it somewhat influences in a negative way (41\%), if the accent is very strong. It is important to mention; however, that most answers made reference to everybody having an accent. 
Graph 7: Negative Influence of an Accent in Teaching

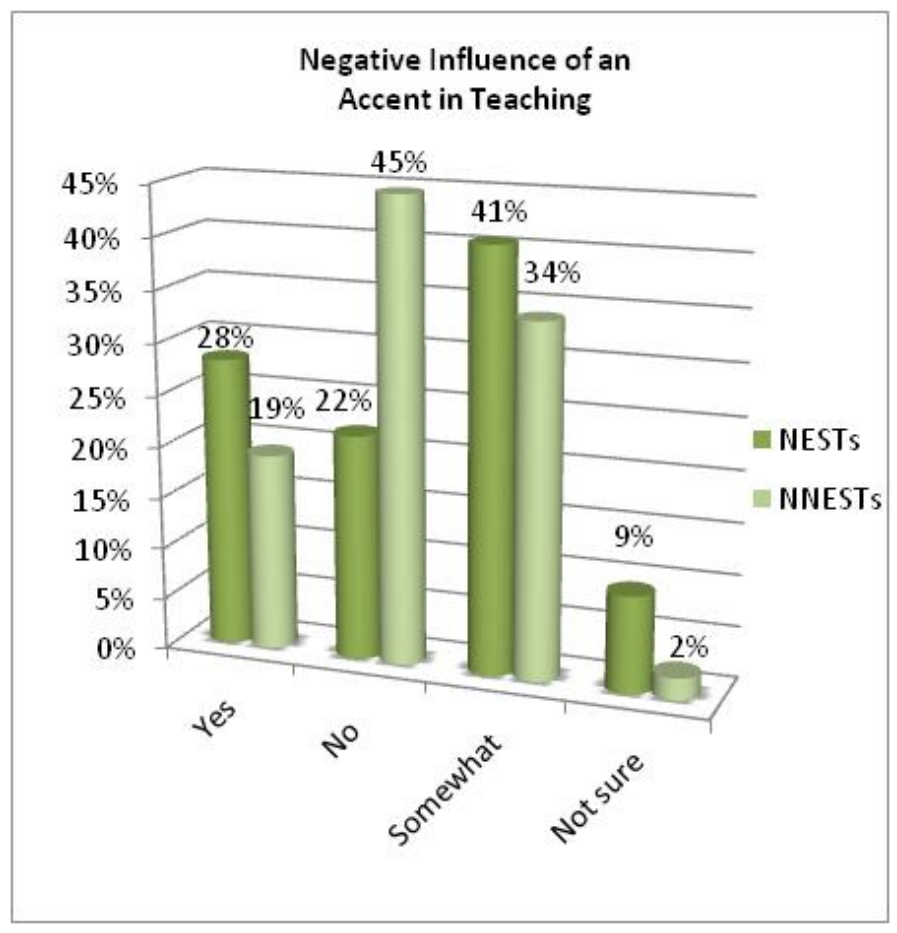

Furthermore, when NNESTs were asked how important it is for them to sound like native speakers, 38\% of them replied very, 23\% somewhat and 21\% not at all. Some reasons they gave were: "I like to be the best role model to my students. Even if I know that there's no perfect speaker”, “The closer you sound like a native speaker, the better”, “I tell my students, 'Look how far I’ve come; so can you’. If I lose my accent completely, I wouldn't be as inspiring to my international students”.

Regarding the need for non-native speakers to have contact with native speakers, NES and NNES teachers agree, exactly with the same percentage, that it is very necessary (60\%). About proficiency, 82\% of NESTs consider it is very important for non-native speakers to be proficient in English; NNESTs think the same way, although this is represented with a higher percentage (96\%). 
Graph 8: Importance for NNESTs to Be Proficient

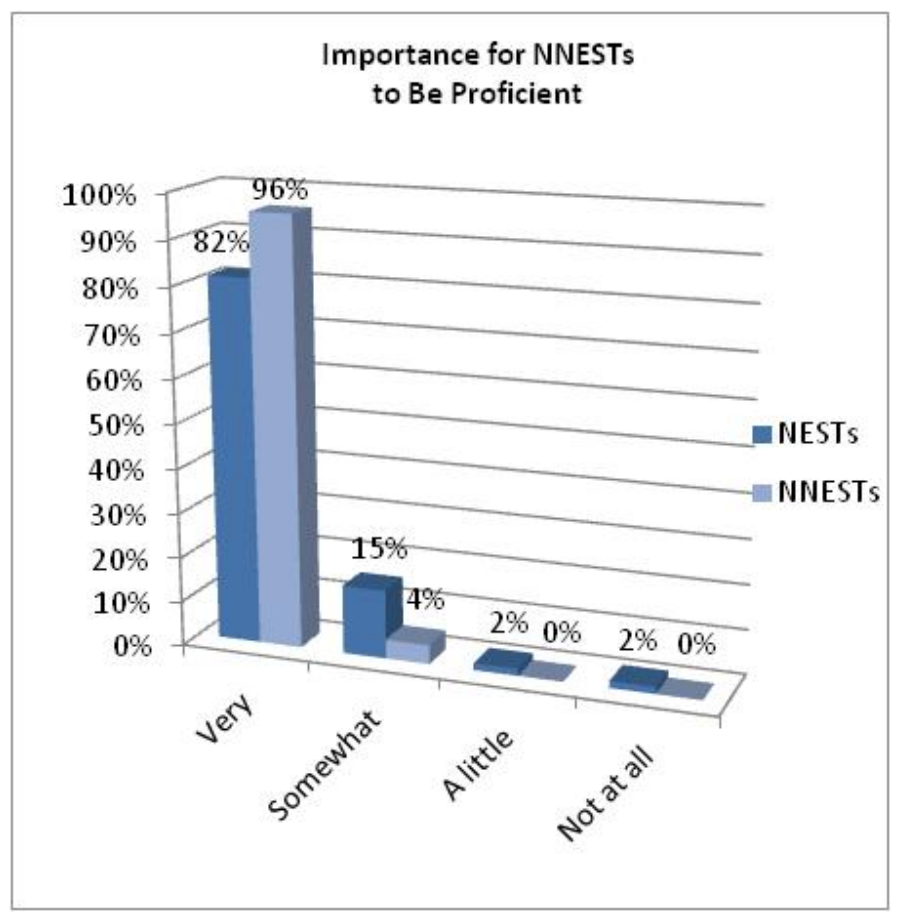

Participants were then inquired if they try to improve or keep up their English skills, to which 89\% replied affirmatively. The most common answers from them were reading, listening to music and videos, watching TV, talking to friends and writing. 59\% said they do it all the time and 34\% do it often; 93\% of them believe that has helped them maintain their English level.

\section{Concluding remarks}

As a growing number of people around the world want to learn English and the number of non-native English teachers is consequently increasing, greater attention is being placed on how those teachers are perceived and what they bring to the language classroom (Moussu and Llurda 2008: 341, 342).

Regardless of the existing belief that native speakers of a language make better teachers, the amount of research questioning it that has been conducted in the past few years is absolutely valuable. Similarly, investigations carried out have given evidence of how 
important it is to recognize the strengths in NES and NNES teachers since both of them can be equally good professionals, in spite of their native and non-native status.

Matsuda (2001) states, “...I cannot emphasize enough that the language background is only one of many factors that define who we are as professionals” (para 10). Indeed, it is completely unreasonable to judge professionals in regards to their native languages alone. The present paper analyzes the results of a survey conducted to English teachers, thus contributing with useful information in this important issue.

[...] it is time for NESTS (sic) to leave the comfort of their nests and see what is happening in the real world” (J. Bear, personal communication, April 13, 2009), and it is time for NNESTs to become more active by 'raising awareness, building advocacy and demonstrating activism (Selvi 2009 in Selvi 2010: 175).

It is clear that a change in the perceptions and attitudes towards non-native speakers must be made in ESL and EFL contexts, that one leading to a fair treatment in hiring practices and credibility in the workplace, from students, administrators, colleagues and NNES teachers themselves.

\section{References}

Braine, G. (2010) NNS English teachers and accents. WATESOL NNEST Caucus Annual Review,1: 15-19. Retrieved 3 April 2010 from http://sites.google.com/site/watesolnnestcaucus/caucus-annual-review

Cheung, Y., Braine, G. (2007) The attitudes of university students towards non-native speakers English teachers in Hong Kong. RELC Journal, 38(3): 257-277. Retrieved 4 October 2010 from http://rel.sagepub.com/content/38/3/257

Cook, V. (1999) Going beyond the native speaker in language teaching. TESOL Quarterly, 33(2): 185-209. Retrieved 30 August 2010 from http://homepage.ntlworld.com/vivian.c/Writings/Papers/NS.htm

Edwards, D. (2010) Arizona cracks down on teachers with heavy accents. The Raw Story. Retrieved 27 May 2010 from http://www.rawstory.com/rs/2010/05/arizonacracks-teachers-accents/

Kachru, B. (2005) Asian Englishes beyond the canon. Hong Kong: Hong Kong University Press.

Mahboob, A. (2005) Beyond the native speaker in TESOL. Culture, Context, \& Communication. 60-93. Retrieved 30 August 2010 from http://www.moussu.net/nnest/articles/Mahboob.pdf 
Matsuda, P.K. (2001) My credo as an NNES professional. NNEST Newsletter, 3(1), 4. Retrieved 23 August 2010 from http://matsuda.jslw.org/abstracts/pdf/tm2003.pdf

Maum, R. (2002). Nonnative-English-speaking teachers in the English teaching profession. Eric Digest. EDO-FL-02-09. Retrieved 2 July 2010 from http://www.cal.org/resources/digest/0209maum.html

Medgyes, P. (2001) When the teacher is a non-native speaker. Teaching pronunciation, 429-442. Retrieved 2 September 2010 from http://teachingpronunciation.pbworks.com/f/When+the+teacher+is+a+nonnative+speaker.PDF

Moussu, L., \& Llurda, E. (2008) Non-native English-speaking English language teachers: History and research. State-of-the-Art Article. Language Teaching. 41(3): 315348. Retrieved 2 July 2010 from http://www2.warwick.ac.uk/fac/soc/al/research/groups/ellta/elted/events/downloa d.pdf

Mydans, S. (2007) Across cultures, English is the word. The New York Times. Retrieved 18 September 2010 from http://www.nytimes.com/2007/04/09/world/asia/09ihtenglede.1.5198685.html?pagewanted=1

Park, S., Shin, S. (2010) "She Immediately Understood What I Was Trying to Say": Student Perceptions of NNESTs as Writing Tutors Pedagogy. WATESOL NNEST Caucus Annual Review, 1: 100-118.

Prabhu, M. (2010) Arizona law worries non-native educators. e-School News,1. Retrieved 27 May 2010 from http://www.eschoolnews.com/2010/05/25/arizona-lawworries-non-native-educators/

Selvi, A. (2010) All teachers are equal, but some teachers are more equal than others: Trend analysis of job advertisements in English language teaching. WATESOL NNEST Caucus Annual Review, 1: 156-181. Retrieved 3 April 2010 from http://sites.google.com/site/watesolnnestcaucus/caucus-annual-review

The British Council. Retrieved 2 July 2010 from http://www.britishcouncil.org/learningfaq-the-english-language.htm

\section{Author references:}

Nuria Villalobos Ulate holds a Master's degree in Linguistics/TESL from Indiana State University, where she was an exchange student from the ISEP program. She has taught English since the year 2000 and has worked with children, adolescents and adults. She is currently a professor at the Escuela de Literatura y Ciencias del Lenguaje at Universidad Nacional, Costa Rica, where she is carrying out post-graduate research. Her research interests include L2 teacher education, global issues in language education, and NNEST-related issues.

\section{Email: nutica@gmail.com}




\section{Appendix}

\section{Survey to Native English-speaking Teachers}

The intention of the following survey is to collect information on the perceptions of native educators in the ELT field. Thank you for your help!

1. How many languages do you speak?

1

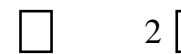

2 $3 \square$ 4 or more

Which ones?

2. Do you think speaking a second language helps teachers better understand their students' learning process?
Yes
No
Somewhat
Not sure

How?

3. Do you teach or have you taught in an ESL environment?

Yes $\square$ No $\square$

4. Do you teach or have you taught in an EFL environment?
Yes
No

5. For you, what is an ideal teacher like?

6. Do you have any preference for teaching certain skills?

(If your answer is negative, please go to question \#9)

Yes $\square$ No $\square$ Somewhat $\square$ Not sure

7. From the following language skills, which ones do you prefer to teach? Number them from 1 to 8 (or 9, if applicable) in order of importance, being \#1 what you like teaching the most.
Grammar $\square$
Speaking
Pronunciation
Listening
Culture
Writing
Reading
Vocabulary
Others

Others:

8. Do you believe this preference for teaching those skills has to do with the fact that you are a native English speaker?

Bellaterra Journal of Teaching \& Learning Language \& Literature. 4.1 (January 2011): 56-79. ISSN 2013-6196. 
Yes No Somewhat Not sure

Why or why not?

9. In your opinion, how necessary is it for an English teacher to be a native English speaker?

Very $\square \quad$ Somewhat $\square \quad$ A little $\square \quad$ Not at all $\square$

Why?

10. Is it better to be taught by a non-native speaker?

Yes $\square \quad$ No $\square \quad$ Somewhat $\square \quad$ Not sure $\square$

Why or why not?

11. Is an English teacher's native language important for students?

Yes $\square$ No $\square \quad$ Somewhat $\square$ Not sure

Why or why not?

12. Who do you think students generally prefer to have as an English teacher?

A non-native speaker $\square \quad$ A native speaker $\square$

No preference $\square \quad$ It depends on the skill taught $\square$

Why?

13. Have you ever experienced any kind of discrimination because of being a native speaker of English?

Yes $\square$ No $\square \quad$ Not sure $\square$

If so, what kind of discrimination?

14. In your opinion, how necessary is it for a non-native English speaker to have contact with native English speakers?

Very $\square \quad$ Somewhat $\square \quad$ A little $\square \quad$ Not at all $\square$

15. How important is it for a non-native English teacher to be proficient in this language?
Very
Somewhat
A little
Not at all

16. Is having an "accent” something that could negatively affect a language educator's teaching?
Yes
No
Somewhat
Not sure

Why or why not?

Bellaterra Journal of Teaching \& Learning Language \& Literature. 4.1 (January 2011): 56-79. ISSN 2013-6196. 
17. If you would like to make any other comment, please do it here:

\section{Survey to Non-native English-speaking Teachers}

The intention of the following survey is to collect information on the perceptions of non-native educators in the ELT field. Thank you for your help!

1. How many languages do you speak? $\square{ }_{1} \quad \square 2 \quad \square 3 \quad \square 4$ or more Which ones?

2. Do you think speaking a second language helps teachers better understand their students' learning process?
Yes
No
Somewhat
Not sure

How?

3. Do you teach or have you taught in an EFL environment?

Yes

No

4. Do you teach or have you taught in an ESL environment?

Yes $\square$ No

5. For you, what is an ideal teacher like?

6. Do you have any preference for teaching certain skills?

(If your answer is negative, please go to question \#9)

Yes $\square \quad$ No $\square \quad$ Somewhat $\square \quad$ Not sure $\square$

7. From the following language skills, which ones do you prefer to teach? Number them from 1 to 8 (or 9, if applicable) in order of importance, being \#1 what you like teaching the most.

\begin{tabular}{|c|c|c|}
\hline Grammar & Speaking & Pronunciation \\
\hline Listening & Culture & Writing \\
\hline Reading & Vocabulary & Others \\
\hline
\end{tabular}

Others:

8. Do you believe this preference for teaching those skills has to do with the fact that you are a nonnative English speaker?

Yes $\square \quad$ No $\square \quad$ Somewhat $\square \quad$ Not sure $\square$

Why or why not?

Bellaterra Journal of Teaching \& Learning Language \& Literature. 4.1 (January 2011): 56-79. ISSN 2013-6196. 
9. In your opinion, how necessary is it for an English teacher to be a native English speaker?
Very $\square$
Somewhat
A little
Not at all

Why?

10. Is it better to be taught by a native speaker?
Yes
No
Somewhat $\square \quad$ Not sure

Why or why not?

11. Is an English teacher's native language important for students?
Yes
No
Somewhat
Not sure

Why or why not?

12. Who do you think students generally prefer to have as an English teacher?
A non-native speaker
A native speaker
No preference
It depends on the skill taught

Why?

13. Have you ever experienced any kind of discrimination because of being a non-native speaker of English?
Yes
No
Not sure

If so, what kind of discrimination?

14. As a non-native English speaking teacher, you probably have an "accent”. Does this bother you? Yes $\square \quad$ No $\square \quad$ Somewhat $\square \quad$ Not sure $\square$

15. Is having an "accent” something that could negatively affect a language educator's teaching?
Yes
No
Somewhat
Not sure $\square$

Why or why not?

16. How important is it for you to sound like a "native speaker"?
Very
Somewhat
A little
Not at all

Why? 
17. Do you try to improve your English skills?
Yes
No
Sometimes

If so, what do you do to improve your skills?

18. Are you doing anything to keep up your English skills?

(If your answer is negative, go to question \#21)

Yes

No

If so, what do you do to keep up your skills?

19. How frequently?
Always
Often
Sometimes
Seldom

20. Has that helped you maintain your English level?
Yes
No
Somewhat
Not sure

21. In your opinion, how necessary is it for a non-native English speaker to have contact with native English speakers?

Very $\square$ Somewhat $\square \quad$ A little $\square \quad$ Not at all

22. How important is it for a non-native English teacher to be proficient in this language?
Very
Somewhat
A little
Not at all

23. If you would like to make any other comment, please do it here: 